\title{
Comparative Evaluation of $N$-Butyl Cyanoacrylate with Braided Silk Suture after Periodontal Flap Surgery: A Randomized Controlled Trial
}

\author{
Sourav Chandra ${ }^{1}$, Pratibha Shashikumar ${ }^{2}$, Swet Nisha ${ }^{3}$
}

\begin{abstract}
Aim and objective: This clinical study was carried out to compare the efficacy of $\mathrm{N}$-butyl cyanoacrylate with braided silk sutures after a periodontal flap surgery in terms of wound healing, postoperative pain experienced by study subjects, and the time required for completion of flap closure. Materials and methods: Forty patients with moderate to severe generalized periodontitis were divided into two treatment groups. Test group ( $N$-butyl cyanoacrylate) and control group (3-0, braided silk sutures). Wound healing, postoperative pain experienced by study subjects, and the time required for completion of flap closure were assessed. Repeated measure ANOVA was done for intragroup comparison at different time intervals. Independent student $t$-test was done for intergroup comparison.

Results: Wound healing was better in the test group in the early stages and postoperative pain and the time required for the flap closure were significantly less in the cyanoacrylate group.

Conclusion: $\mathrm{N}$-Butyl cyanoacrylate is a reliable alternative to conventional sutures as it is easy to apply, shortens the operation time, causes a less inflammatory response, and reduces postoperative pain while facilitating primary closure similar to conventional silk sutures.

Clinical significance: $\mathrm{N}$-Butyl cyanoacrylate a newer tissue adhesive is painless, biocompatible, better tissue handling, less time-consuming, and better acceptability by the patient for the closure of flaps than silk sutures.

Keywords: Cyanoacrylates, Flap surgery, Silk sutures, Tissue adhesives.

World Journal of Dentistry (2021): 10.5005/jp-journals-10015-1847
\end{abstract}

\section{INTRODUCTION}

Periodontal diseases induce hard and soft tissue changes that require surgical intervention. Flap surgeries are routinely performed for the management of these changes. Primary closure of flap margins is a very important aspect of the treatment outcome as it is the key to the establishment of a healthy dentogingival unit. ${ }^{1}$ Even though silk sutures have long been used for flap closure they are found to have inflammatory tissue response and act as a reservoir for secondary infection. To overcome these drawbacks, the need for a better alternative is always present. One such alternative is a group of tissue adhesives called cyanoacrylates. ${ }^{2}$ Cyanoacrylate preparations have been used for $>50$ years in surgery. Initially used as surgical glue, they polymerize rapidly within seconds when they come in contact with proteinaceous surfaces to form strong and flexible bonds. Because of this chemical property, they are extensively used in different surgical applications in the field of general and dental surgical procedures. ${ }^{3}$

Cyanoacrylates as tissue adhesives were discovered by Coover and others in 1959. The general formula of these cyanoacrylates is $\mathrm{CH}_{2} \hat{\mathrm{m} C} \mathrm{C}-\mathrm{COOR}$, where $\mathrm{R}$ may represent a methyl, propyl, or butyl radical. ${ }^{4}$ Several studies have been carried out using either the methyl or butyl cyanoacrylates on animals. ${ }^{5}$ DeRenzis and Aleo compared the relative cytotoxic effects of methyl, isobutyl, and octyl-cyanoacrylate when applied to L929 fibroblasts. The cytotoxic effects were greatest with the methyl and less severe with the isobutyl and octyl-cyanoacrylates. ${ }^{6}$

Studies with humans have involved the use, almost exclusively, of the less toxic isobutyl cyanoacrylates. Isobutyl cyanoacrylate has been demonstrated as the least toxic of the cyanoacrylates
${ }^{1-3}$ Department of Periodontology, JSS Dental College and Hospital, JSS Academy of Higher Education and Research, Mysuru, Karnataka, India Corresponding Author: Swet Nisha, Department of Periodontology, JSS Dental College and Hospital, JSS Academy of Higher Education and Research, Mysuru, Karnataka, India, Phone: +91 7595800724, e-mail: swetnisha1@gmail.com

How to cite this article: Chandra S, Shashikumar P, Nisha S. Comparative Evaluation of $N$-Butyl Cyanoacrylate with Braided Silk Suture after Periodontal Flap Surgery: A Randomized Controlled Trial. World J Dent 2021;12(4):328-332.

Source of support: Nil

Conflict of interest: None

to the tissues. ${ }^{7}$ The advantage of butyl cyanoacrylate adhesives over conventional ones is that they function without the use of special catalysts. The polymerization of the liquid monomer to solid polymer takes place rapidly within seconds in the presence of small quantities of moisture. ${ }^{7}$ Along with adhesive properties butyl cyanoacrylates are known to be bacteriostatic, hemostatic, and are well tolerated by the tissue. ${ }^{8}$

An in vitro study on rabbits assessed gene expression and autogenous grafts were fixed in the mandible with cyanoacrylate and compared with screw fixation concluded the cyanoacrylate caused less inflammation and higher mineralized volume of tissue. ${ }^{9}$ Cyanoacrylate as an adhesive for resorbable membrane fixation was used in the case report which showed esthetic results at a 4-year follow-up period. ${ }^{10}$ Cyanoacrylate has been used as adhesive in root coverage procedures like free gingival grafts. ${ }^{11}$ Ozcan et al. 
demonstrated donor site healing after free gingival graft harvesting was accelerated after placement of cyanoacrylate in palatal area. ${ }^{12}$

Periodontal wound healing is an important event in the treatment outcome. Primary closure of the site can assure wound stability and promote early tissue maturation and healing. Initial wound stabilization is achieved by suturing during the early wound healing phase; however, sutures can harbor microorganisms and delay the healing response. Soni et al. compared sutures with cyanoacrylates for wound closure and found the time required in the cyanoacrylate group was significantly less for wound closure than the suture. ${ }^{13}$ Another study aimed at evaluation of hemostasis, inflammation, and infection postsurgery in cyanoacrylate and suture concluded that hemostasis was immediately achieved with cyanoacrylates with no intraoral tissue reactions and any complications. ${ }^{14}$ Nevins et al. used cyanoacrylate in extraction socket as a protective layer with collagen membrane and found its biocompatibility in periodontal tissue regeneration. ${ }^{15}$ Gumus and Buduneli showed significantly less graft contraction, minimal postoperative pain, and no bleeding complications in the cyanoacrylate group in comparison with suture and microsurgery. ${ }^{16}$

$\mathrm{N}$-Butyl cyanoacrylate is a newer tissue adhesive material that is biocompatible with the stronger tissue-binding property even in moist environments and can be used as an alternative to silk, nylon, or staples. This unique property of tissue-binding of cyanoacrylate was utilized in this study to compare the efficacy of $\mathrm{N}$-butyl cyanoacrylate with braided silk sutures after a periodontal flap surgery in terms of wound healing, postoperative pain experienced by study subjects, and the time required for completion of flap closure.

\section{Materials and Methods}

Forty patients with moderate to severe generalized periodontitis (i.e., probing depth of $\geq 5 \mathrm{~mm}$ ) in the age group of 20-60 years and acceptable oral hygiene visiting the Department of Periodontology, JSS Dental College and Hospital were included in this study. Both anterior and posterior quadrants were considered in the study. Patients' consent and institutional ethical clearance were obtained before the study. Patients with known systemic diseases and/or drug therapy, deleterious habits of smoking or tobacco chewing, and pregnant or lactating mothers were excluded from the study. The sample size was calculated based on the previous study. ${ }^{17}$ The calculated sample size was 40 (20 subjects in each group).

The study patients were further divided into two treatment groups. Test group $(n=20)$ in which the flaps were secured with the help of by $N$-butyl cyanoacrylate (TruSeal: Suture India Pvt. Ltd) and control group $(n=20)$ in which the flaps were secured with the help of 3-0 braided Silk Sutures (Lifesilk: Sutures India Pvt. Ltd.).

\section{Presurgical Preparation}

The surgical procedure was explained in detail to the study subjects along with instructions on proper oral hygiene. All the subjects underwent thorough scaling and root planning and were recalled for follow-up.

\section{Surgical Procedure}

The patients were randomized into either the cyanoacrylate group (test group) or suture group (control group) using the computer-assisted randomization technique. Local anesthetic was administered using 2\% lignocaine hydrochloride with 1:80,000 adrenaline in the area to be operated. The surgical procedure involved the elevation of a mucoperiosteal flap followed by debridement and root planing. Flap closure was done either by $\mathrm{N}$-butyl cyanoacrylate in the test group or 3-0 black braided silk sutures in the control group according to the allocation. In the test group after holding the flap in the final closure position, $\mathrm{N}$-butyl cyanoacrylate (Truseal) was applied in a drop-wise manner at the flap margins until a thin film of the adhesive was formed (Fig. 1A). In the control group, the flap was secured by independent loop sutures (Fig. 2A). No periodontal dressing was given in either of the groups. Analgesics paracetamol $500 \mathrm{mg}$ twice daily for 3 days was prescribed in both groups. The time required for the closure of the wound was recorded in seconds for each patient. Postoperative instructions were given. Patients were given a visual analog scale to record the intensity of the postoperative pain experienced. Patients were also evaluated for the following parameters; TureskyGlickman-Gilmore modification of Quigley-Hein Plaque Index, ${ }^{18}$ Gingival index, ${ }^{19}$ and wound healing index $(\mathrm{WHI})^{20}$ on $3 \mathrm{rd}, 7$ th, 14th, and 21st postoperative days. Digital photographs were taken for all the patients at each visit (Figs $1 \mathrm{~B}$ and $\mathrm{C}$ and Figs 2B and C).

\section{Statistical Analysis}

Statistical analyses were performed with statistical software (SPSS for Windows, Version 16.0, SPSS Inc., Chicago, IL, USA). Repeated measure ANOVA was done for intragroup comparison at different time intervals. Independent student $t$-test was done for intergroup comparison. The level of significance was set at $p<0.05$.

\section{Results}

The control group consisted of 20 subjects with 9 women and 11 men. The mean age in this group was $43 \pm 0.66$ years, ranging from 35 to 69 years. The test group consisted of 20 subjects with 8 women and 12 men (mean age $46 \pm 0.32$ ) (Table 1).

Table 2 shows the comparison of plaque scores between test and control groups at different time intervals. At a 3-day recall postoperative in the control group, the mean plaque score was $1.3 \pm 0.56$ which was reduced to $0.78 \pm 0.05$ at a 21 -day interval. In the test group, the mean plaque score at the $3 \mathrm{rd}$-day recall visit was $0.78 \pm 0.60$ and at the 21 -day interval, it was $0.81 \pm 0.09$. There was a statistically significant difference between the test and control group on 3rd and 7th $(p<0.05)$, whereas on the 14th- and 21st-day, plaque index in the test group was not significantly different from the control group. The test group showed considerably less plaque accumulation compared to the control group during the 3rd-and 7th-day postoperatively.

Table 3 shows the comparison of the gingival index between test and control groups at different time intervals. The mean gingival index in the control group at the $3 \mathrm{rd}$ - and 21 st-day interval was $1.96 \pm 0.14$ and $0.72 \pm 0.07$, respectively. In the test group, it was $0.86 \pm 0.15$ at the 3 rd-day and $0.76 \pm 0.05$ at the 21 -day follow-up. There was a statistically significant difference between test and control groups on the 3rd and 7th day $(p<0.05)$, whereas this difference was not significant on the 14th and 21st day $(p>0.05)$. The test group showed less gingival inflammation on the 3rd and 7 th day.

Table 4 shows the comparison of the wound healing index between test and control groups at different time intervals. The mean wound healing index at the 3rd-day recall visit was $1.9 \pm$ 0.14 and $0.95 \pm 0.11$ at the 21 st-day follow-up period in the control group. In the test group at the $3 \mathrm{rd}$ mean wound healing index was $1.2 \pm 0.15$ which was reduced to $0.93 \pm 0.15$ at the 21 st-day follow-up 

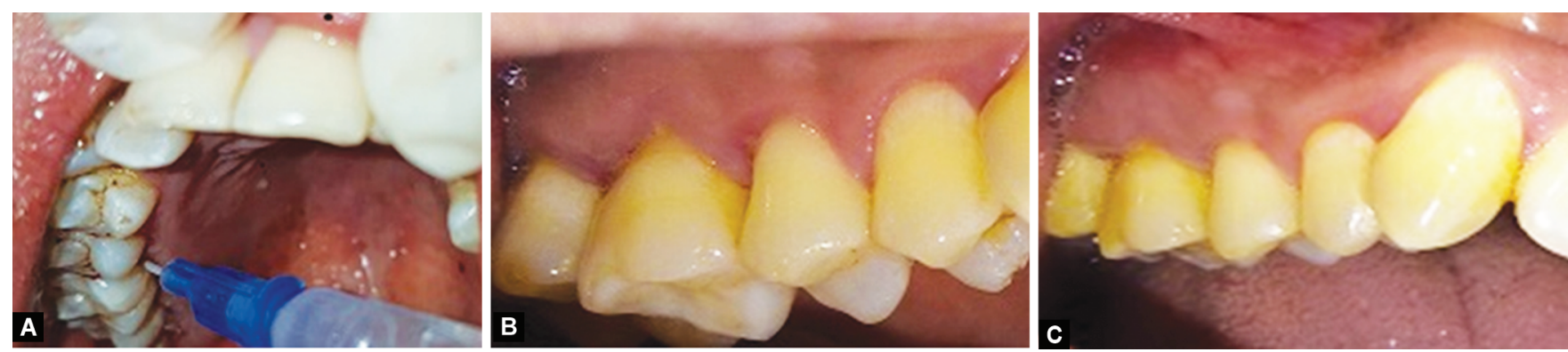

Figs $1 \mathrm{~A}$ to $\mathrm{C}$ : Clinical photographs of cyanoacrylate glue test group after periodontal flap surgery: (A) at baseline, (B) on 7th postoperative day, and (C) on 21st postoperative day
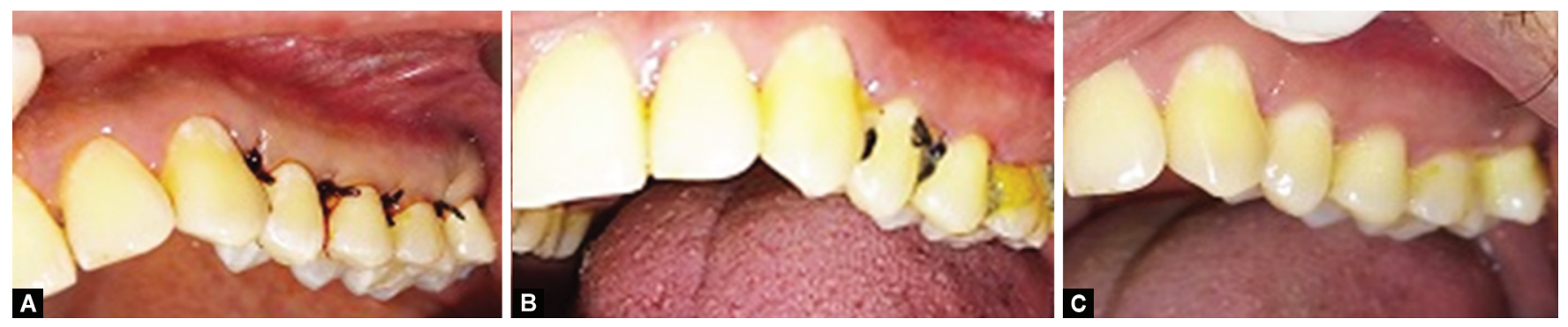

Figs 2A to C: Clinical photographs of silk suture control group after periodontal flap surgery: (A) at baseline, (B) on 7th postoperative day, and (C) on 21st postoperative day

Table 1: Demographic parameters of different groups in the study

\begin{tabular}{lll}
\hline Variables & Control & Test \\
\hline Age in years (mean \pm SD) & $43 \pm 0.66$ & $46 \pm 0.32$ \\
Gender & 20 & 20 \\
Male & 11 & 12 \\
Female & 9 & 8 \\
\hline
\end{tabular}

SD, standard deviation

period. Wound healing was found to be better in the test group on $3 \mathrm{rd}$. However, there was no statistically significant difference in the wound healing on 14th and 21st day between the groups (Fig. 3).

The comparison of VAS scores between test and control groups is shown in Table 5. The mean VAS score in the test group on the 3rd day was $4.45 \pm 1.13$ and on the 21 st day $0.05 \pm 0.23$. The mean VAS score in the control group on the 3rd day was $5.1 \pm 0.9$ and on the 21 st day $(0.20 \pm 0.41)$. The subjects in the test group experienced significantly less postoperative pain during the first 7 days $(p<0.05)$. The VAS scores during the consecutive visits showed no significant difference between the test and control groups ( $p>0.05)$.

Plaque scores in the control group were considerably higher compared to the test group on the first week as sutures acted as plaque retentive areas and subjects were unable to carry out proper oral hygiene. The same was true when it came to gingival inflammation during the first 3 days. The presence of sutures caused more inflammation in the control group. Sutures can act as a nidus for microbial plaque retention and hence increased gingival inflammation. Once the sutures were removed there was no significant difference in both plaque and gingival index scores between both the groups.

\section{Discussion}

The tissue changes that occur as a result of periodontal disease require surgical intervention many times. Primary closure and stabilization of flaps become an important aspect of postoperative healing. Since sutures have their own drawbacks quest for quicker and safer adhesives is always there. $N$-Butyl cyanoacrylate is one such tissue adhesive that has shown promising results in animal studies. ${ }^{21}$ It is shown to be biocompatible with good working properties in presence of moisture and has a setting time of 5-10 seconds. This study was carried out to compare $N$-butyl cyanoacrylate and braided silk sutures in the closure of periodontal flaps and also its effect on wound healing and postoperative pain experienced was assessed. Control group patients showed more plaque retention than the test group as postoperative maintenance of oral hygiene was difficult with the sutures present as opposed to the smooth surface provided by the application of cyanoacrylate. These findings were in accordance with the results of studies done by Giray et al. ${ }^{22}$

The $\mathrm{N}$-butyl-2-cyanoacrylate has been used widely in the field of medicine and dentistry. It is used as an adhesive tissue and has hemostasis, bacteriostatic, and rapid adhesion to both soft and hard tissues. It has a long half-life and biocompatible with gradual resorption. It can set in presence of moisture and blood in 5-10 seconds and releases heat on the setting. In dentistry, it has been used as a wound-healing agent in procedures like free gingival graft, apicoectomy, root sectioning, bonding of fractured tooth fragments. Intraoral wound closure in cases of biopsies, fractures, excision, and surgeries. ${ }^{23}$ This adhesive acts as a hemostatic agent in the extraction site. In the field of esthetic surgery, it is used in wound closure, skin grafting, face, and brow lifts.

Contraindications of its uses are patients allergic to cyanoacrylate, in stress and tension bearing areas like joint, friction infectious area with exudates like a periodontal abscess. ${ }^{24}$

Cyanoacrylate requires no needle application, reduces puncture risk, accidental clinicians' pricks, and can be used in cases where the anesthetic effect is reduced. It does not exhibit systemic toxicity or mucosa irritation with minimal incidents of necrosis. 
Table 2: Intergroup comparison of plaque index

\begin{tabular}{cccccc}
\hline & \multicolumn{3}{c}{ Mean $\pm S D$} & & \\
Time interval (days) & \multicolumn{1}{c}{ Control } & Test & Difference in mean & t value & Significance $\left(p^{*}\right)$ \\
\hline 3 & $1.3 \pm 0.56$ & $0.78 \pm 0.60$ & -0.02 & 0.3 & $0.000^{*}$ \\
7 & $1.1 \pm 0.21$ & $0.76 \pm 0.13$ & 0.86 & 1.09 & $0.000^{*}$ \\
14 & $0.8 \pm 0.15$ & $0.77 \pm 0.09$ & 0.04 & 0.98 & 0.17 \\
42 & $0.78 \pm 0.05$ & $0.81 \pm 0.09$ & 0.03 & 0.87 & 0.43 \\
\hline
\end{tabular}

*Statistically significant

Table 3: Intergroup comparison of gingival index

\begin{tabular}{cccccc}
\hline & \multicolumn{2}{c}{ Mean \pm SD } & & \\
\cline { 2 - 5 } Time interval (days) & Control & Test & Difference in mean & t value & Significance $\left(p^{*}\right)$ \\
\hline 3 & $1.96 \pm 0.14$ & $0.86 \pm 0.15$ & -0.04 & 0.70 & $0.000^{*}$ \\
7 & $1.9 \pm 0.21$ & $0.94 \pm 0.11$ & 0.86 & 9.7 & $0.000^{*}$ \\
14 & $1.2 \pm 0.15$ & $0.95 \pm 0.13$ & 0.09 & 1.7 & 0.16 \\
42 & $0.72 \pm 0.07$ & $0.76 \pm 0.05$ & 0.04 & 1.3 & 0.52 \\
\hline
\end{tabular}

*Statistically significant

Table 4: Intergroup comparison of wound healing index

\begin{tabular}{cccccc}
\hline & \multicolumn{3}{c}{ Mean \pm SD } & & \\
\cline { 2 - 5 } Time interval (days) & \multicolumn{1}{c}{ Control } & \multicolumn{1}{c}{ Test } & Difference in mean & t value & Significance $\left(p^{*}\right)$ \\
\hline 3 & $1.9 \pm 0.14$ & $1.2 \pm 0.15$ & 0.7 & 1.42 & $0.03^{*}$ \\
7 & $1.8 \pm 0.18$ & $1.3 \pm 0.13$ & 0.5 & 1.38 & $0.04^{*}$ \\
14 & $1.4 \pm 0.16$ & $1.2 \pm 0.12$ & 0.2 & 6.2 & 0.43 \\
42 & $0.95 \pm 0.11$ & $0.93 \pm 0.15$ & 0.3 & 5.8 & 0.41 \\
\hline
\end{tabular}

*Statistically significant $p<0.05$

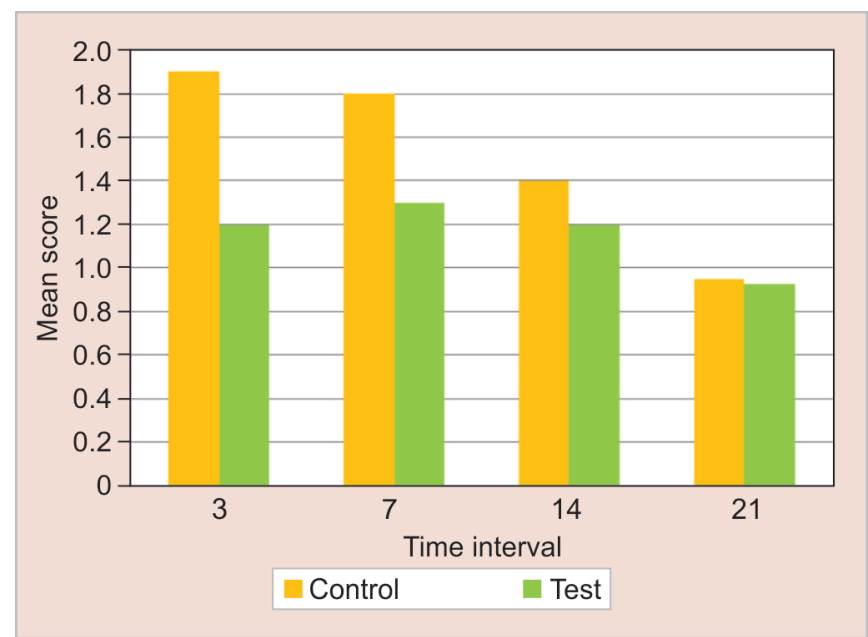

Fig. 3: Comparison of wound healing index in test and control groups at different time intervals

Reduce tensile strength, high cost is the potential disadvantages of cyanoacrylate. ${ }^{25}$

Inflammatory tissue response to the suture materials can be clinically assessed by gingival index. In our study, the inflammatory response was more pronounced in the control group on the $3 \mathrm{rd}$ and 7th days. This can be attributed to the presence of silk sutures in the tissues and increased plaque accumulation as stated by Macht and Krizek ${ }^{26}$ and Giray et al. ${ }^{27}$ However, Giray et al. attributed it to the trauma during suturing and plaque accumulation. Since the sutures were removed on 7th day, there was no difference in the tissue response between the groups on 14th and 21st day. Our findings were similar to studies conducted by Greer. ${ }^{28}$

The wound healing index has been used by many authors to assess the healing after flap surgery. In this study, wound healing was significantly better in the cyanoacrylate group during the first 7 days after which both the groups showed similar healing. Our findings were similar to that of Khurana et al. ${ }^{29}$ Study subjects in the test group experienced less postoperative pain during the first 7 days. This could be attributed to the trauma during suturing in the control group. Similar findings were reported by Mahajani et al. who assessed postoperative pain using a questionnaire and found the pain experienced was similar in both groups. ${ }^{30}$

The time required for suturing was significantly more in the control group ( $589.5 \pm 82.23$ seconds) than that in the test group (264.35 \pm 37.98 seconds), because of ease of application and good working and handling properties of cyanoacrylate. There were no reports of adverse reactions to the cyanoacrylate material in the test group subjects.

\section{Strength and Limitations}

Previous studies were done only in anterior teeth, this study with an adequate sample size assesses the material both in anterior and posterior teeth. However, due to ethical reasons, histological sections of the sutured and cyanoacrylate sites were not taken to correlate the clinical findings. 
Table 5: Intergroup comparison of VAS score

\begin{tabular}{cccccc}
\hline & \multicolumn{3}{c}{ Mean $\pm S D$} & & \\
\cline { 2 - 5 } Time interval (days) & Control & \multicolumn{1}{c}{ Test } & Difference in mean & t value & $0.000^{*}$ \\
\hline 3 & $5.1 \pm 0.9$ & $4.45 \pm 1.13$ & 0.7 & 1.9 & $0.000^{*}$ \\
7 & $3.9 \pm 1.5$ & $3.1 \pm 1.82$ & 0.75 & 1.3 & 0.42 \\
14 & $0.65 \pm 1.1$ & $0.90 \pm 1.12$ & 0.25 & 0.70 & 0.31 \\
42 & $0.20 \pm 0.41$ & $0.05 \pm 0.23$ & 0.15 & 1.43 & 0.31 \\
\hline
\end{tabular}

*Statistically significant

\section{Conclusion}

It can be concluded that $N$-butyl cyanoacrylate is a reliable alternative to conventional sutures as it is easy to apply, less timeconsuming, causes a less inflammatory response, and reduces postoperative pain while facilitating primary closure similar to conventional silk sutures.

\section{References}

1. Takei HH, Carranza FA, Jonathan H. Do: the periodontal flap Newman T, Klokkevold C, ed. Textbook of Carranza's clinical periodontology. 12th ed., Elsevier; 2015. pp. 582-586.

2. Miller GM, Dannenbaum R, Cohen DW. A preliminary histologic study of the wound healing of mucogingival flaps when secured with the cyanoacrylate tissue adhesives. J Periodontol 1974;45(8):608-618. DOI: 10.1902/jop.1974.45.8.2.608.

3. Habib A, Mehanna A, Medra A. Cyanoacrylate: a handy tissue glue in maxillofacial surgery: our experience in Alexandria, Egypt. J Maxillofac Oral Surg 2013;12(3):243-247. DOI: 10.1007/s12663-012-0433-z.

4. Coover HWJr, Toyner FP, Shearer NHJr, et al. Chemistry and performance of cyanoacrylate tissue adhesives. Soc Plastic Engineers J 1959;15:413.

5. Binnie WH, Forrest JO. A study of tissue response to cyanoacrylate adhesive in periodontal surgery. J Periodontol 1974;45(8):619-625. DOI: 10.1902/jop.1974.45.8.2.619.

6. DeRenzis FA, Aleo JJ. An in vitro bioassay of cyanoacrylate cytotoxicity. Oral Surg, Oral Med, Oral Pathol 1970;30(6):803-808. DOI: 10.1016/0030-4220(70)90344-0.

7. Forrest JO. The use of cyanoacrylates in periodontal surgery. J Periodontol 1974;45(4):225-229. DOI: 10.1902/jop.1974.45.4.225.

8. Bhaskar SN, Frisch J. Use of cyanoacrylate adhesives in dentistry. J Am Dent Assoc 1968;77(4):831-837. DOI: 10.14219/jada.archive.1968.0310.

9. Salata LA, Mariguela VC, Antunes AA, et al. Short-term evaluation of grafsfxed with either $\mathrm{N}$-butyl-2-cyanocrylate or screws. J Oral Maxillofac Surg 2014;72(4):676-682. DOI: 10.1016/j.joms.2013.11.016.

10. Rezende MLRD, Cunha PDO, Damante CA, et al. Cyanoacrylate adhesive as an alternative tool for membrane fixation in guided tissue regeneration. J Contemp Dent Pract 2015;16(6):512-518. DOI: 10.5005/jp-journals-10024-1714.

11. Tavelli L, Asa'ad F, Acunzo R, et al. Minimizing patient morbidity following palatal gingival harvesting: a randomized controlled clinical study. Int J Periodont Restorat Dentis 2018;38(6):e127-e134. DOI: $10.11607 /$ prd.3581.

12. Ozcan $M$, Ucak $O$, Alkaya B, et al. Efects of platelet-rich fbrin on palatal wound healing after free gingival graft harvesting: a comparative randomized controlled clinical trial. Int J Periodont Restorat Dentis 2017;37(5):270-278. DOI: 10.11607/prd.3226.

13. Soni R, Narula A, Kumar M, et al. Comparing cyanoacrylate tissue adhesive and conventional subcuticular skin sutures for maxillofacial incisions - a prospective randomized trial considering closure time, wound morbidity, and cosmetic outcome. J Oral Maxillofac Surg 2013;71(12):2152.e1-2152.e8. DOI: 10.1016/j.joms.2013.08.029.

14. Perez M, Fernandez I, Marquez D, et al. Use of N-butyl-2cyanoacrylate in oral surgery: biological and clinicalevaluation.
Artific Organs 2000;24(3):241-243. DOI: 10.1046/j.1525-1594.2000. 06519.x.

15. Nevins M, Mendoza-Azpur G, Angelis ND, et al. The biocompatibility of cyanoacrylate tissue adhesive inconjunction with a collagen membrane for providing soft andhard tissue regeneration in extraction socket preservation procedures. Int J Periodont Restorat Dentis 2018;38:s37-s42. DOI: 10.11607/prd.3770.

16. Gumus P, Buduneli E. Graft stabilization with cyanoacrylatedecreases shrinkage of free gingival grafts. Australian Dent J 2014;59(1):57-64. DOI: $10.1111 / a d j .12149$.

17. Kulkarni S, Dodwad V, Chava V. Healing of periodontal flaps when closed with silk sutures and N-butyl cyanoacrylate: a clinical and histological study. Indian J Dent Res 2007;18(2):72-77. DOI: 10.4103/0970-9290.32424.

18. Turesky S, Gilmore ND, Glickman I. Reduced plaque formation by the chloromethyl analogue of victamine C. J Periodontol 1970;41(1):4143. DOI: 10.1902/jop.1970.41.41.41.

19. Loe H, Silness J. Periodontal disease in pregnancy. I. Prevalence and severity. Acta Odontol Scand 1963;21(6):533-551. DOI: 10.3109/00016356309011240.

20. Huang LH, Neiva RE, Wang HL. Factors affecting the outcomes of coronally advanced flap root coverage procedure. J Periodontol 2005;76(10):1729-1734. DOI: 10.1902/jop.2005.76.10.1729.

21. Kulkarni SS, Chava VK. Comparison of cyanoacrylate and silk sutures on healing of oral wounds--an animal model study. Indian J Dent Res 2003;14(4):254-258.

22. Giray CB, Atasever A, Durgun B, et al. Clinical and electron microscope comparison of silk sutures and n-butyl-2-cyanoacrylate in human mucosa. Aust Dent J 1997;42(4):255-258. DOI: 10.1111/j.18347819.1997.tb00130.x.

23. Borie E, Rosas E, Kuramochi G, et al. Oral applications of cyanoacrylate adhesives: a literature review. Bio Med Res Int 2019. 1-5.

24. Leggat PA, Smith DR, Kedjarune U. Surgical applications of cyanoacrylate adhesives: a review of toxicity. ANZ J Surg 2007;77(4):209-213. DOI: 10.1111/j.1445-2197.2007.04020.x.

25. Petrie ME. Cyanoacrylate adhesives in surgical applications. Rev Adhes Adhesi 2014;2(3):253-310. DOI: 10.7569/RAA.2014.097306.

26. Macht SD, Krizek TJ. Sutures and suturing-current concepts. J Oral Surg 1978;36(9):710-712.

27. Giray $C B$, Sungur $A$, Atasever $A$, et al. Comparison of silk sutures and n-butyl-2-cyanoacrylate on the healing of skin wounds. A pilot study. Aust Dent J 1995;40(1):43-45. DOI: 10.1111/j.1834-7819.1995.tb05613.x.

28. Greer Jr RO. Studies concerning the hsitotoxicity of isobutyl2-cyanoacrylate tissue adhesive when employed as an oral hemostat. Oral Surg Oral Med Oral Pathol 1975;40(5):659-669. DOI: 10.1016/0030-4220(75)90376-X.

29. Khurana JV, Mali AM, Mali RS, et al. Comparative evaluation of healing after periodontal flap surgery using isoamyl 2-cyanoacrylate (bioadhesive material) and silk sutures: a split-mouth clinical study. J Indian Soc Periodon 2016;20(4):417-422. DOI: 10.4103/0972124X.194267.

30. Mahajani A, Menaka KB, Jagirdar SAA, et al. Evaluation of antibacterial efficacy and healing with cyanoacrylate tissue adhesive after periodontal flap surgery. Clin Dentis 2019;XIII:12-17. DOI: 10.33882/ ClinicalDent.13.24801. 